\title{
Quality of blended learning as perceived by Arab Open University students
}

\author{
Mohammad Abdel-Rahman Tawalbeh \\ Department of Education Studies, Arab Open University, Jordan
}

\begin{tabular}{l}
\hline \hline Article Info \\
\hline Article history: \\
Received Nov 9, 2019 \\
Revised Apr 30, 2020 \\
Accepted Jun 23, 2020 \\
\hline
\end{tabular}

\section{Keywords:}

Blended learning

Classroom tutorial

E-learning

LMS

Perception

\begin{abstract}
The primary goal of this research was to investigate AOU students' conceptions of the quality of online experience through the learning management system in supporting their classroom tutorials. A 32-item questionnaire was administered to a randomly selected sample (205) of Elementary Education students at the AOU Jordan Branch. On one hand, the results showed that the objectives of the courses were very clear to students, online materials on the learning management system were interesting and supported to classroom learning, students preferred online quizzes, the online materials supported key assessment tasks and tutors provided continuous access to relevant information about assessment. On the other hand, the findings revealed that the online materials and e-activities were too loaded for the students to understand thoroughly, and much of the feedback they received from the tutor was not helpful. The results also indicated that there were no statistically significant differences among students' views of BL or their overall satisfaction of the online experience that could be attributed to gender or academic achievement level. Results suggest some pedagogical implications for tutors and programmer coordinators.
\end{abstract}

This is an open access article under the CC BY-SA license.

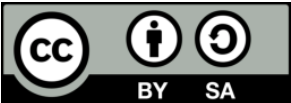

\section{Corresponding Author:}

Mohammad Tawalbeh,

Department of Education Studies, AOU, Jordan,

P.O. Box 1339 Amman 11953 Jordan.

Email: m_tawalbeh@aou.edu.jo

\section{INTRODUCTION}

Traditional institutions encounter some challenges to cope with the innovations and demands of students' daily life pressures. Lifelong learning and the use of ICT are primary reasons for that. Adults are increasingly returning to institutions of higher education to pursue their study whilst in full-time employment.

To address this increasing demand, the AOU was opened in October 2002 to offer students in the Arab world opportunities of higher education by adopting open BL and utilizing state-of-the-art information and communication technologies at reasonable costs. After 18 years of its establishment, the AOU has witnessed some developments with regard to learning and teaching environments. The delivery of instruction through LMS in combination with traditional classroom tutorials is what distinguishes the AOU from other universities in the Arab region. This combination of synchronous and asynchronous online and classroom instruction is called BL.

Researchers [1] investigated the effect of BL on the achievement of undergraduate students in multimedia courses. The results showed that students in the BL group got better scores than the students who studies in a classroom mode and they engaged in discussions more actively. ICTs are also used to facilitate and enhance interaction between students [2]. Indeed, some researchers [3, 4] pointed out that student-teacher 
communication [through LMS] can assist students to raise their academic achievement and stimulations. Other researchers [5] asserted that the LMS provides a suitable environment for students to communicate, collaborate with peers and tutors to learn together and engage with online tools [6].

Results of recent studies [7] revealed that BL is more effective in enhancing students' learning achievement. This strategy also meets students' satisfaction and offers rich learning experiences, particularly at higher education sector [8-10].

There is little research about the relationship of students' learning experiences and the online part of their courses [11]. It is believed that students' views of learning constitute an essential part in their learning.

In this context researchers [11] conducted a study in which they investigated veterinary science learners' views of the learning environment. In the first part of their study, they examined students' views about learning in an online context. They found that students' response were not overly positive. However, their study found that students' interaction was very high.

Moreover, other researchers [12-14] found that optimistic views of online learning associated with positive outcomes. Indeed, a recent study [15] recommended conducting more research to find out the effect of LMS on learners performance and views. Therefore, this study seeks to examine students' views of the quality of on-line resources in supporting their classroom learning.

The central objective of this study was to investigate the AOU students' views of their experience on how online might support their classroom tutorials. The tool for collecting data in this survey study was the questionnaire. The main question of this study was:

How do AOU students perceive the quality of online learning in supporting their classroom tutorials? More specifically, this study addressed the following questions:

Q1: How did AOU students perceive learning in a BL context in supporting their classroom tutorials?

Q2: How did AOU students perceive their interaction and engagement in an online environment in supporting their classroom tutorials?

Q3: How did AOU students perceive the clarity of objectives of the e-part in supporting their classroom tutorials?

Q4: How did AOU students perceive e-resources in supporting their classroom tutorials?

Q5: How did AOU students perceive the appropriateness of assessment in an online context in supporting their classroom tutorials?

Q6: How did AOU students perceive the appropriateness of the workload related to online context in supporting their classroom tutorials?

Q7: How did AOU students perceive issues related to students management in supporting their classroom tutorials?

Q8: How did AOU students perceive BL and overall contentment with online experience through the LMS in supporting their classroom tutorials?

Q9: Was there any gender differences $(\alpha=0.05)$ amongst AOU students in the views of BL and overall contentment with online experience through the LMS in supporting their classroom tutorials?

Q10: Were there any differences $(\alpha=0.05)$ attributed to academic achievement level amongst AOU students in their point of views of BL and overall contentment with their online experience?

A 32-item questionnaire was adopted in this study, which was originally developed by Ginns and Ellis [11]. The questionnaire is called "Course Experience Questionnaire" (CEQ). It was based on the scales developed by some researchers [12, 16-20], and studies mostly focused on higher education learners' experience in e- learning and the relation of their performance to the intended learning outcomes [21]. This scale comprised of 2 parts. The first part is the demographic data. The second part had 8 sections. The first section (seven items) dealt with the quality of instruction in a BL context. The second section incorporated four items about students' interaction and engagement. The third section included three items on the clarity of objectives of the online part of the course. The fourth section included four items about the quality of eresources. The fifth section included three items about the appropriateness of assessment. The sixth section included three items about the appropriateness of the workload related to e-resources. The seventh section included three items about students' management. Finally, the eight sections included five items dealing with students' overall satisfaction with online materials and activities in supporting classroom learning. All items of the questionnaire were adapted to the goals of this study and translated to Arabic. The questionnaire distributed to students was in English and Arabic, however.

The questionnaire (translated to Arabic) was passed to and collected from students by the researcher himself in Summer 2018/2019.

Panel of ten faculty members from the Universities of Yarmouk and AOU reviewed the instrument and offered suggestions regarding additions or deletions to enhance the content validity of the questionnaire. Feedback was used in clarifying some words, statements, as well as the translation of some items. The overall opinion of the judges showed that the questionnaire was suitable to be used in the study. 
Responses of thirty five (35) subjects were analyzed to test the reliability of each section of the questionnaire. This randomly selected sample was later excluded from the final sample used in the study. The calculated Cronbach alpha coefficient was 0.79 for Section1, 0.81 for Section 2, 0.70 for Section 3, 0.75 for Section 4, 0.70 for Section 5, 0.71 for Section 6, 0.80 for Section 7, 0.88 for Section 8, and 0.85 for the whole questionnaire. This suggested that this instrument was suitable to measure AOU students' views of the quality of adopting BL in their education. This research is restricted by the sample that was chosen from the Jordan Branch of the AOU. Thus, generalization of results is limited to this audience. The study is also restricted to the scale used in this survey.

\section{RESEARCH METHOD}

This study is mainly quantitative in nature and was conducted using a survey method. The population of this study is 303 Elementary Education students registered in summer semester 2018/2019 at the AOU Jordan Branch. The sample $(n=205)$ was randomly chosen representing about $(67.7 \%)$ of the population. Demographic data is shown in the Table 1.

Table 1. Sample demographics

\begin{tabular}{lccc}
\hline \multicolumn{1}{c}{ Variables } & & No. & Percentage \\
\hline \multirow{2}{*}{ Gender } & Male & 29 & $14.15 \%$ \\
& Female & 176 & $85.85 \%$ \\
& A & 35 & $17.08 \%$ \\
Academic achievement level & B & 63 & $30.73 \%$ \\
& C & 49 & $23.90 \%$ \\
& D & 40 & $19.51 \%$ \\
& F & 18 & $8.78 \%$ \\
& Total & 205 & $100.00 \%$ \\
\hline
\end{tabular}

Students' responses to the Likert scale (agree $=3$, neutral $=2$, disagree $=1$ ) of all subjects, were entered into the SPSS (reversing negative items). Descriptive statistics, t-test and ANOVA were carried out to answer the questions of the study,

\section{RESULTS AND DISCUSSION}

\subsection{Results and analysis of the first eight questions}

The first eight questions investigate subjects' responses to the 32 items of the Quality of BL measurement tool. The items were distributed into eight domains; each one provides data to answer a question of this study. It can clearly be noticed that the students' responses to all items in the domains were overly positive except, for their response to the sixth domain that deals with appropriateness of workload.

Table 2 shows that the tutors' answers through the LMS motivated the students to learn more deeply (item 2). However, although they received much feedback (item 1) from their tutors, students believed that much of it was not he

Table 2. Answer to question (Q1)

\begin{tabular}{clrc}
\hline No. & & Mean & S.D. \\
\hline 1 & I received too much feedback through the LMS from my tutor. & 2.47 & 0.73 \\
2 & The tutor's responses through the LMS motivated me to learn more deeply. & 2.50 & 0.64 \\
3 & The tutor helped to guide discussions between students through the LMS. & 2.34 & 0.69 \\
4 & The tutor's interaction with me through the LMS encouraged me to get the most out of my & 2.43 & 0.68 \\
& learning. & & \\
5 & The tutor's responses through the LMS motivated me to do more on-line learning than I & 2.29 & 0.72 \\
& would have done otherwise. & 2.21 & 0.78 \\
6 & I didn't receive enough helpful feedback from my tutor through the LMS. & 2.34 & 0.64 \\
7 & The tutor helped to focus on discussions between students through the LMS. & 2.37 & 0.68 \\
Total & & &
\end{tabular}

In Table 3, the results suggest that other students' submissions appear to be more helpful to clarify their own ideas (item 8) than investigating further sources of knowledge (item 11). Moreover, this domain scored the second least overall mean (2.35) indicating that students were not encouraged to interact and engage in LMS activities 
Table 3. Answer to question (Q2)

\begin{tabular}{|c|c|c|c|}
\hline No. & Items & Mean & S.D. \\
\hline 8 & Reading other students' submissions through the LMS clarified some of my own ideas. & 2.41 & 0.60 \\
\hline 9 & I interacted with students' submissions through the LMS even if they weren't assessed. & 2.31 & 0.75 \\
\hline 10 & $\begin{array}{l}\text { Other students' submissions through the LMS helped me understand my ideas from a new } \\
\text { perspective. }\end{array}$ & 2.32 & 0.71 \\
\hline 11 & $\begin{array}{l}\text { Other students' submissions through the LMS encouraged me to investigate further sources of } \\
\text { knowledge. }\end{array}$ & 2.35 & 0.74 \\
\hline Total & & 2.35 & 0.67 \\
\hline
\end{tabular}

Table 4 reveals that "clarity of objectives of the e-part" domain scored the highest overall mean (2.66) indicating that information and guidelines related to the course content, forums, and assignment were very clear to the majority of the students. Indeed item 14 scored the highest of the 32 items (2.83). This finding seems to be logical, and indicates that academic and administrative monitoring in the branch is well conducted.

Table 4. Answer to question (Q3)

\begin{tabular}{|c|c|c|c|}
\hline No. & Items & Mean & S.D. \\
\hline 12 & $\begin{array}{l}\text { Information needed to understand the purpose and contents of the courses was integrated in one } \\
\text { place on the LMS. }\end{array}$ & 2.64 & 0.58 \\
\hline 13 & The guidelines for using discussions were clear to me through the LMS. & 2.49 & 0.66 \\
\hline 14 & Information needed for assignments was integrated in the one place through the LMS. & 2.83 & 0.42 \\
\hline Total & & 2.66 & 0.54 \\
\hline
\end{tabular}

Table 5 shows that students perceived the online material to be interesting (item 17) and as supportive of classroom tutorial (item 18).

Table 5. Answer to question (Q4)

\begin{tabular}{|c|c|c|c|}
\hline No. & Items & Mean & S.D. \\
\hline 15 & The online materials in the courses are extremely good at explaining many related issues. & 2.44 & 0.66 \\
\hline 16 & The activities on the LMS are designed to get the best out of students. & 2.41 & 0.66 \\
\hline 17 & The online materials are designed to really try to make topics interesting to students. & 2.30 & 0.69 \\
\hline 18 & The online materials helped me to learn during the classroom tutorial of the courses I studied. & 2.51 & 0.69 \\
\hline Total & & 2.41 & 0.65 \\
\hline
\end{tabular}

Table 6 shows that the "appropriateness of assessment" domain scored the second highest overall mean (2.62), indicating that students prefer online quizzes (items 19 and 20).

Table 6. Answer to question (Q5)

\begin{tabular}{|c|c|c|c|}
\hline No. & Items & Mean & S.D. \\
\hline 19 & To do well in the on-line quizzes all you really need is a good memory. & 2.72 & 0.65 \\
\hline 20 & The on-line quizzes helped me to learn effectively. & 2.59 & 0.54 \\
\hline 21 & The online materials on the LMS supported some key assessment items in the courses I studied. & 2.55 & 0.58 \\
\hline Total & & 2.62 & 0.55 \\
\hline
\end{tabular}

Table 7 reveals that this domain scored the least overall mean (1.84), indicating that the load related to the online materials and e-activities was too heavy (item 22) and was very difficult for the students to understand it thoroughly.

Table 7. Answer to question (Q6)

\begin{tabular}{|c|c|c|c|}
\hline No. & Items & Mean & S.D. \\
\hline 22 & The workload of the e-part of the courses is too heavy. & 1.53 & 0.71 \\
\hline 23 & I generally had enough time to understand the things I had to learn through the LMS. & 2.13 & 0.78 \\
\hline 24 & $\begin{array}{l}\text { The sheer volume of work for the e-part of the courses means it can't all be thoroughly } \\
\text { comprehended. }\end{array}$ & 1.86 & 0.73 \\
\hline Total & & 1.84 & 0.70 \\
\hline
\end{tabular}

J. Edu. \& Learn. Vol. 14, No. 3, August 2020 : 449 - 455 
Table 8 shows that leaners were most positive about the degree to which the instructor make available constant access to relevant information about the results (item 25) and online materials (items 26 and 27).

Table 8. Answer to question (Q7)

\begin{tabular}{clrr}
\hline No. & \multicolumn{1}{c}{ Items } & Mean & S.D. \\
\hline 25 & $\begin{array}{l}\text { The tutor utilized online environment when appropriate to keep students up to date about } \\
\text { outcomes. }\end{array}$ & 2.61 & 0.60 \\
26 & $\begin{array}{l}\text { The tutor used the online environment to regularly bring up to date students about relevant } \\
\text { course information. }\end{array}$ & 2.54 \\
& & 0.65 \\
27 & The tutor guarantees constant access to the pertinent online materials all through the semester. & 2.51 & 0.65 \\
Total & & 0.61 \\
\hline
\end{tabular}

Table 9 shows that the students had positive views about the degree to which the online materials and e-activities on the LMS support classroom learning (items 28, 29, 30, and 31) and reported equally positive attitudes towards the overall contentment with the quality of the online materials and e-activities (item 32).

Table 9. Answer to question (Q8)

\begin{tabular}{|c|c|c|c|}
\hline No. & Item & Mean & S.D. \\
\hline 28 & It was clear if the LMS resources were related to assessment. & 2.50 & 0.66 \\
\hline 29 & $\begin{array}{l}\text { The e-activities on the LMS helped me to understand the classroom activities in the courses I } \\
\text { studied. }\end{array}$ & 2.45 & 0.67 \\
\hline 30 & $\begin{array}{l}\text { The relationship between the e-resources and the whole units of the courses was clarified on } \\
\text { the LMS. }\end{array}$ & 2.49 & 0.65 \\
\hline 31 & It was clear to me how a part of a unit on the LMS is related to the whole unit of a course. & 2.56 & 0.64 \\
\hline 32 & Overall, I was happy with the quality of the online materials and e-activities. & 2.53 & 0.64 \\
\hline Total & & 2.50 & 0.63 \\
\hline
\end{tabular}

The results of the first eight questions revealed an interesting view, along with others, that highlights the importance of e-activities in promoting collaborative learning and discussion between students. The use of Moodle LMS may help students to work as a learning community as it is believed that "continuing chat between students and [tutors] about a course and activities may ease students' capability to value learning as an interactive, social activity" $[22,23]$. This notion of learning is consistent with the present widespread socioconstructivism [24], which emphasizes learning as a social and interactive activity. Indeed, the results of some studies [25] showed that learners who failed a course spent a shorter time in group communications.

\subsection{Results and discussion of the ninth question}

The ninth question examines if there was a gender difference in students' perceptions of BL and overall agreement with online learning. The independent t-test shows that there was no statistically significant difference $(\alpha=0.05)$ between gender groups.

This result might be due to the fact that both females and males enjoy similar learning environments at AOU, with equal access to the LMS. The low number of male students (29) as opposed to the high number of females 176 might have affected the result as well, as shown in Table 10.

Table 10. Answer to question (Q9)

\begin{tabular}{lcccccc}
\hline & Gender & $\mathbf{N}$ & Mean & S.D. & t & Sig \\
\hline Students & Female & 176 & 2.51 & 0.54 & 0.45 & 0.65 \\
views & Male & 29 & 2.46 & 0.50 & & \\
\hline
\end{tabular}

\subsection{Results and discussion of the tenth question}

The tenth question investigates if there were differences in the students' views of BL and overall accordance with their online practice due to academic achievement level (A, B, C, D, or F). The results of the ANOVA in Table 11 show that there were no statistically significant differences $(\alpha=0.05)$ that can be attributed to differences between the various academic achievement levels. This is a trending significance, though. So, there could be some effect of academic level on views.

This result suggests that the students use the LMS in the same manner regardless their different achievement levels. Moreover, the result seems to be logical as all students with different achievement levels 
have to get benefit of the online materials and e-activities on the LMS which constitute a fundamental support for their classroom learning.

Table 11. Answer to question (Q10)

\begin{tabular}{llccccc}
\hline & & Sum of Squares & df & Mean Square & F & Sig. \\
\hline \multirow{2}{*}{ Student Views } & Between Groups & 2.518 & 4 & .629 & 2.270 & 0.063 \\
& Within Groups & 55.450 & 200 & .277 & & \\
& Total & 57.968 & 204 & & & \\
\hline
\end{tabular}

\section{CONCLUSION}

This study investigated AOU students' perceptions of the quality of online learning in supporting their classroom tutorials. The findings of this research suggested that students' responses were overly positive except towards the domain which deals with workload. The online materials and e-activities were overloaded for them to thoroughly comprehend. Although students receive much advice and guidance from their tutors, much of it was not helpful enough. The objectives of the e-part of the courses were understandable to students, online materials on the LMS were motivating and supporting to classroom learning, students preferred online quizzes, the online materials supported key assessment tasks, and instructors offered constant access to proper information about results. Regardless of gender and academic achievement, however, students were happy with the quality of online materials and e-activities in supporting their classroom learning.

This study bridges the gap in research by looking at the relationship of learners' experiences across all courses on the LMS to their classroom learning. Results from this study have some implications for educators who are involved in BL. Tutors are advised to pay more attention to the quality of feedback by making it more informative so as to help students figure out their pitfalls. The university should continue the process of computerizing exams. Tutors should also pay attention to the quality of online materials and eactivities by deciding the extent to which they contribute to the classroom learning. Also, tutors and programmer coordinators should advice student about their study load in relation to their other occupational and personal commitments. Tutors should encourage their students to be more interactive and engaged in the LMS by activating the course forum and online communication office hours.

This study advanced current research and recommend more research as follows: 1) conducting another study to investigate how online is being employed to complement the classroom tutorials of the other three AOU based program; 2) exploring the views of learners with varying learning styles on how online environment may support their classroom tutorials; 3) replicating the study at other branches of AOU by adding some qualitative measures such as semi-structured interviews for the purpose of cross validation.

\section{REFERENCES}

[1] H, Surjono, A. Muhtadi, and D. Wahynigsih, "The implementation of blended learning in multimedia courses for undergraduate students in Indonesia," International Journal of Information and Education Technology, vol. 7, no. 10 , pp. $783-786,2017$

[2] I. Hussain, O. Cakir, and U. Candeger, "Social media as a learning technology for university students," International Journal of Instruction, vol. 11, no. 2, pp. 281-296, 2018.

[3] G. Burdina, I. Krapotkina, and L. Nasyrova, "Distance learning in elementary school classrooms: An emerging framework for cotemporary practice," International Journal of Instruction, vol. 12, no. 1, pp. 1-16, 2019.

[4] C. Dziuban, et al., "Blended learning: The new normal and emerging technologies," International Journal of Educational Technology in Higher Education, vol. 15, no. 1, pp. 1-16, 2018.

[5] R. Magdalene and D. Sridharan, "Powering e-learning through technology: an overview of recent trends in educational technologies," The Online Journal of Distance Education and E-Learning, vol. 6, no. 1, pp. 60-65, 2018.

[6] N. Zanjari, S. Edwards, S. Nykvist, and S. Geva, "The important elements of LMS design that affect user engagement with e-learning tools within LMSs in the higher education sector," Australasian Journal of Educational Technology, vol. 33, no. 3, pp. 19-31, 2017.

[7] R. Tamim, "Blended learning for learner empowerment: Voices from the Middle East," Journal of Research on Technology in Education, vol. 50, no. 1, pp.70-83, 2018.

[8] F. Harahap, N. Nasution, and B. Manurung, "The effect of blended learning on student's learning achievement and science process skills in plant tissue culture course," International Journal of Instruction, vol. 12, no. 1, pp. 521-538, 2019.

[9] A. Al-Qahtani and S. Higgins, "Effects of traditional, blended and e-learning on students achievement in higher education," Journal of Computer Assisted Learning, vol. 29, no. 3, pp. 220-234, 2013.

[10] L. Al-Hyari, "The impact of using blended learning strategy on the achievement of the students of university of Jordan in the English language course," Dirasat Educational Sciences, vol. 46, no. 2, pp. 23-34, 2019. 
[11] P. Ginns and R. Ellis, "Quality in BL: Exploring the relationships between on -line and face-to face-teaching and learning," Internet and Higher Education, vol. 10, no. 1, pp. 53-64, 2007.

[12] A. Lizzio, K. Wilson, and R. Simon, "University students' perceptions of the learning environment and academic outcomes: Implications for theory and practice," Studies in Higher Education, vol. 27, no. 1, pp. 27-51, 2002.

[13] K. Bhagat, Y. Wu, and Y. Chang, "Development and validation of the perception of students towards online learning (POSTOL)," Journal of Educational Technology and Society, vol. 19, no. 1, pp. 350-359, 2016.

[14] J. Bowers and P. Kumar, "Students perceptions of teaching and social presence: A comparative analysis of face-toface and online learning environments," International Journal of Web-based Learning and Teaching Technologies (IJWLTT), vol. 10, no. 1, pp. 27-44, 2015.

[15] A. Alzahrani, "The effect of distance learning delivery method on students' performance and perception," International Journal for Research in Education, vol. 43, no. 1, pp. 293-311, 2019.

[16] K. Crawford, S. Gordon, J. Nicholas, and M. Prosser, "Qualitatively different experiences of learning mathematics at university," Learning and instruction, vol. 8, no. 5, pp. 455-468, 1998.

[17] C. Lawless and J. Richardson, "Approaches to study and perceptions of academic quality in distance education," Higher Education, vol. 44, no. 2, pp. 275-282, 2002.

[18] P. Ramsden, "A performance indicator of teaching quality in higher education: The course experience questionnaire," Studies in Higher Education, vol. 16, no. 2, pp. 129-150, 1991.

[19] A. Richardson, "A British evaluation of the course experience questionnaire," Studies in Higher Education, vol. 19, no. 1, pp. 59-68, 1994.

[20] K. Wilson, A. Lizzio, and P. Ramsden, "The development, validation and application of the course experience questionnaire," Studies in Higher Education, vol. 22, no. 1, pp. 33-53, 1997.

[21] P. Ramsden, Learning to teach in higher education. London: Routledge, 2002.

[22] L. Phelan, "Interrogating students' perceptions of their online learning experiences with Brookfield's critical incident questionnaire," Distance Education, vol. 33, vol. 1, pp. 31-44, 2012.

[23] W. Yu and X. Du, "Implementation of a blended learning model in content-based EFL curriculum," International Journal of Emerging Technologies in Learning, vol. 14,no. 05, pp. 188-199, 2019.

[24] S. Dawson, "A study of the relationship between student communication interaction and sense of community," The Internet and Higher Education, vol. 9, no. 3, pp. 153-162, 2006.

[25] J. Davies and M. Graff, "Performance in e-learning: On-line participation and student grades," British Journal of Education Technology, vol. 36, no. 4, pp. 657-663, 2005.

\section{BIOGRAPHY OF AUTHOR}

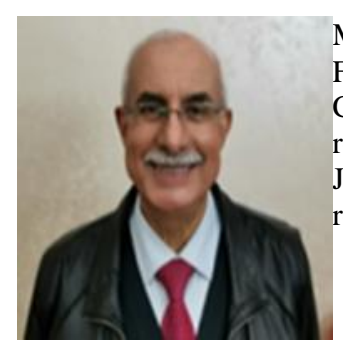

Mohammad Tawalbeh is a professor of Educational Technology and currently the Dean of the Faculty of Education and General Studies at the Arab Open University. He obtained his Ph.D. in Computer Based Learning from Leeds University/UK. He published more than 25 articles in peer reviewed journals, supervised more than 35 M.Ed. Dissertations and 10 Ph.D. Theses at some Jordanian and Arab universities during the last 25 years, and he is an editorial member and reviewer of some journals. His major research areas are: Open, online, and blended learning. 